\title{
Kinetics analysis of two-stage austenitization in supermartensitic stainless steel
}

Nießen, Frank; Villa, Matteo; Hald, John; Somers, Marcel A. J.

Published in:

Materials \& Design

Link to article, DOI:

10.1016/j.matdes.2016.11.076

Publication date:

2017

Document Version

Peer reviewed version

Link back to DTU Orbit

Citation (APA):

Nießen, F., Villa, M., Hald, J., \& Somers, M. A. J. (2017). Kinetics analysis of two-stage austenitization in supermartensitic stainless steel. Materials \& Design, 116, 8-15. https://doi.org/10.1016/j.matdes.2016.11.076

\section{General rights}

Copyright and moral rights for the publications made accessible in the public portal are retained by the authors and/or other copyright owners and it is a condition of accessing publications that users recognise and abide by the legal requirements associated with these rights.

- Users may download and print one copy of any publication from the public portal for the purpose of private study or research.

- You may not further distribute the material or use it for any profit-making activity or commercial gain

- You may freely distribute the URL identifying the publication in the public portal

If you believe that this document breaches copyright please contact us providing details, and we will remove access to the work immediately and investigate your claim 


\section{Kinetics analysis of two-stage austenitization in supermartensitic stainless}

\section{steel}

Frank Niessen $^{1, a^{*}}$, Matteo Villa ${ }^{2, b}$, John Hald ${ }^{2, c}$ and Marcel A.J. Somers ${ }^{2, d}$

${ }^{1}$ Technical University of Denmark (DTU), Danish Hydrocarbon Research and Technology Centre (DHRTC), 2800 Kgs. Lyngby, Denmark

${ }^{2}$ Technical University of Denmark (DTU), Department of Mechanical Engineering, 2800 Kgs. Lyngby, Denmark

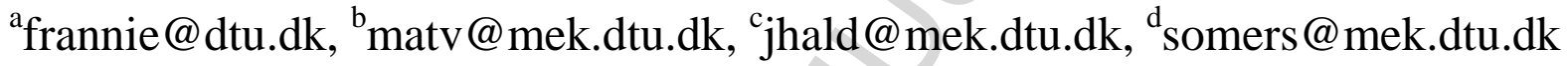

Abstract. The martensite-to-austenite transformation in X4CrNiMo16-5-1 supermartensitic stainless steel was followed in-situ during isochronal heating at 2, 6 and $18 \mathrm{~K} \cdot \mathrm{min}^{-1}$ applying energy-dispersive synchrotron X-ray diffraction at the BESSY II facility. Austenitization occurred in two stages, separated by a temperature region in which the transformation was strongly decelerated. The region of limited transformation was more concise and occurred at higher austenite phase fractions and temperatures for higher heating rates. The two-step kinetics was reproduced by kinetics modeling in DICTRA. The model indicates that the austenitization kinetics is governed by Ni-diffusion and that slow transformation kinetics separating the two stages is caused by soft impingement in the martensite phase. Increasing the lath 
width in the kinetics model had a similar effect on the austenitization kinetics as increasing the heating-rate.

Keywords: supermartensitic stainless steels; phase transformation kinetics; interface diffusion; synchrotron radiation; kinetics modeling; reversed austenite 


\section{Introduction}

Supermartensitic stainless steels are low carbon lath martensitic steels based on the Fe-Cr-Ni system [1,2]. This class of steels has gained popularity in the oil and gas sector as a low cost alternative to highly alloyed duplex stainless steels in pipeline applications [3].

The excellent strength and toughness properties are obtained through inter-critical annealing (tempering below $\mathrm{A}_{3}$ temperature) to promote the formation of lamellar reversed austenite on high- and low-angle boundaries of lath martensite [4-7]. The annealing leads to an effective decrease of the average grain size and to a "composite structure" of hard tempered martensite and soft austenite. During plastic deformation, such a structure hinders dislocation movement over long distances. Reversed austenite was furthermore reported to strengthen the material during plastic deformation by transformation induced plasticity (TRIP) [8-11].

The formation of lamellar austenite was reported to be promoted by the establishment of an energetically favorable phase-interface (Kurdjumov-Sachs [1215]), and might be affected by residual stress of the martensite transformation and grain-boundary segregation [16]. Partitioning of $\mathrm{Ni}$ is a well-documented mechanism of stabilizing reversed austenite to room temperature [8,17-20]. Furthermore, the internal substructure of austenite [8] and the size and shape distributions of the austenite regions [10], were suggested to affect thermal stability. With increasing 
annealing temperature, the austenite was reported to approach a coarser, spherodized morphology, which decreases the phase stability upon cooling [10].

Studies on isochronal heating of different steel alloys have shown that austenitization can occur in multiple stages [21-27]. In all these cases two-stage austenitization was found to be based on a given or evolving inhomogeneous microstructure during heating, which gave rise to locally varying driving forces for austenite formation, dissolution of phases and related diffusion or shear processes.

Bojack et al. showed in a comprehensive in-situ study that also $13 \mathrm{Cr} 6 \mathrm{Ni} 2 \mathrm{Mo}$ supermartensitic stainless steel exhibits two distinct stages of austenite formation during isochronal heating [23]. In a later study the two-stage austenitization kinetics was analyzed with a Kissinger-like method applying a range of heating rates [22]. It was suggested that the two-step kinetics was a result of solute redistribution during the growth of austenite. The first stage was assumed to be mainly caused by partitioning of $\mathrm{Ni}$ and $\mathrm{Mn}$ and the second stage by dissolution of carbides and increased diffusivity of $\mathrm{Ni}$ and $\mathrm{Mn}$. Two-stage austenitization kinetics was also observed for austenitization of $\mathrm{X} 4 \mathrm{CrNiMo16-5-1}$ (EN 1.4418) supermartensitic stainless steel by dilatometry and in-situ synchrotron X-ray diffraction [28].

The kinetics of the two transformation stages in both investigated supermartensitic stainless steels depended on heating rate, thus it appears as if they are governed by a thermally activated process [18]. From the listed investigations on the multi-stage austenitization kinetics in different steel alloys, all thermally activated 
transformations were identified as diffusion controlled. Therefore it appears as if the responsible mechanisms for two stage austenitization can be identified from kinetics modeling of the diffusion process.

As part of a physics-based modeling framework Galindo-Nava et al. modelled diffusion controlled reversion of austenite from lath martensite during isothermal holding based on transformation of a single lath [29]. The model describes the grain boundary kinetics dependent on the geometrical constraints of the lath, the equilibrium phase fraction of austenite and an effective diffusivity parameter. The model successfully predicted the austenite phase fraction during isothermal annealing in a range of alloys, but does not take multicomponent diffusion into account. Thus the well-documented solute partitioning during austenite reversion $[8,17-20]$, which according to Bojack et al. is responsible for the two-step kinetics [22], is not reflected in such a model.

Esin et al. modelled two stage austenitization from cementite and ferrite in a lowalloy steel using the kinetics model for diffusion controlled transformations DICTRA [21]. In this study the two stage austenitization was shown to depend on the redistribution of carbon from the inhomogeneous initial microstructure of cementine and ferrite. The kinetics model DICTRA is suited to simulate diffusion controlled transformations in multi-component systems by numerically solving the multicomponent diffusion equation, and thus appears ideal for the analysis of austenitization of supermartensitic stainless steel in two stages. Therefore, in the 
present work, the martensite-to-austenite transformation in a $\mathrm{X} 4 \mathrm{CrNiMo16-5-1}$ was followed in-situ with energy-dispersive synchrotron X-ray diffraction and analyzed with kinetics modeling in DICTRA.

\section{Experimental procedure}

\subsection{Material and heat treatments}

Samples were machined from a $\emptyset 10 \mathrm{~mm}$ rod EN 1.4418 steel grade in as-extruded condition. The composition of the alloy is given in Table 1. The samples for energy dispersive synchrotron X-ray diffraction (XRD) were ground to $\varnothing 10 \mathrm{~mm} \times 0.15 \mathrm{~mm}$ discs and subsequently electro-polished for $30 \mathrm{~s}$ at $25 \mathrm{~V}$ with Struers A2 electrolyte to reduce the strain-affected layer in the surface. Prior to investigation, samples were normalized at $950{ }^{\circ} \mathrm{C}$ for $10 \mathrm{~min}$ in an Ar flow. The average heating and cooling rate were 45 and $70 \mathrm{~K} \cdot \mathrm{min}^{-1}$, respectively.

The sample for characterization by Transmission Kikuchi Diffraction, was prepared from a dilatometry specimen, for which isochronal heating with $15 \mathrm{~K} \cdot \mathrm{min}^{-1}$ was interrupted at $650^{\circ} \mathrm{C}$. The sample was a thin foil which was thinned by electrolytic twin-jet polishing in $10 \%$ perchloric acid dissolved in ethanol at $-20{ }^{\circ} \mathrm{C}$.

\subsection{Energy dispersive synchrotron $\mathrm{X}$-ray diffraction}

The investigation was carried out at the EDDI-beamline at the synchrotron facility HZB-BESSY II [30]. It consisted of a series of isochronal heating tests at applied heating rates 2, 6 and $18 \mathrm{~K} \cdot \mathrm{min}^{-1}$ within the temperature interval $25-920{ }^{\circ} \mathrm{C}$. Specimens were mounted on an Anton Paar DHS 1100 Domed Hot Stage and 
investigated under continuous Ar flow. The temperature was measured with a thermocouple attached to the heating stage. The experiments were conducted in a symmetric diffraction geometry with a constant scattering angle $2 \theta=14^{\circ}$ and a $2 \mathrm{x}$ $0.5 \mathrm{~mm}$ primary slit configuration. In energy-dispersive X-ray diffraction all reflections are acquired simultaneously, which enables accurate quantitative phase analysis over temperature. Diffraction peaks occur for certain energies $E_{h k l}$, which are a function of the respective interplanar spacing, $d_{h k l}$, and the fixed scattering angle, $2 \theta[31]$. The diffraction peaks were fitted with a Pseudo-Voigt profile and the phase fractions were determined by the direct comparison method [32]. Detailed descriptions of the procedures applied for peak fitting and quantitative phase analysis are reported in [28].

\subsection{Transmission Kikuchi Diffraction}

Transmission Kikuchi Diffraction (TKD) was carried out on electro-polished thin foils in an FEI Nova NanoLab 600 scanning electron microscope. The Kikuchi patterns were acquired with a Bruker e-Flash EBSD detector, configured with a horizontal OPTIMUS TKD detector head. No tilt was applied to the sample. The working distance was $3 \mathrm{~mm}$, the acceleration voltage $30 \mathrm{kV}$, the beam current $1.7 \mathrm{nA}$ and the step-size in-between successive TKD patterns was $16 \mathrm{~nm}$. The orientation data were cleaned and smoothed by a minimum grain-size criterion and a smoothing spline filter by using the texture analysis software MTEX [33]. 


\section{Experimental Results}

\subsection{Energy dispersive synchrotron $\mathrm{X}$-ray diffraction}

The measured transformation curves in Figure 1a show that transformation occurs in the temperature range $570{ }^{\circ} \mathrm{C}$ to $925{ }^{\circ} \mathrm{C}$. The initial fraction of retained austenite was about $5 \pm 1 \mathrm{vol} . \%$ for all investigated conditions. A change in heating rate from 2 to $18 \mathrm{~K} \cdot \mathrm{min}^{-1}$ led to a shift of the temperature of maximum transformation rate from 640 to $670{ }^{\circ} \mathrm{C}$. Upon further heating the transformation to austenite slowed down. For heating at $2 \mathrm{~K} \cdot \mathrm{min}^{-1}$ the deceleration smoothly developed into the second stage of austenitization. For heating at 6 and $18 \mathrm{~K} \cdot \mathrm{min}^{-1}$, the deceleration approached an actual interruption of the transformation and two steps can be discerned clearly. The minimum transformation rate for the heating rates 2,6 and $18 \mathrm{~K} \cdot \mathrm{min}^{-1}$ are reached at 763,763 and $760{ }^{\circ} \mathrm{C}$, respectively, at austenite fractions of 71,74 and 76 vol. \%, respectively. Further heating led to a new increase in the transformation rate, which again showed a shift to higher temperature of fastest transformation for faster heating; the maximum transformation rate is observed at 846,866 and $925{ }^{\circ} \mathrm{C}$ for 2,6 and $18 \mathrm{~K} \cdot \mathrm{min}^{-1}$, respectively. The contribution of a thin oxide layer to the diffraction patterns was apparent above $900{ }^{\circ} \mathrm{C}$ for heating with $2 \mathrm{~K} \cdot \mathrm{min}^{-1}$ and excluded from phase quantification.

Evidently, reversed austenite formation takes place in two-steps and the heating rate defines the maxima of the transformation rate. Supplementary measurements of 
the transformation kinetics with dilatometry for heating rates 2-100 K.min ${ }^{-1}$ consistently yielded two-stage transformation kinetics [28].

a)

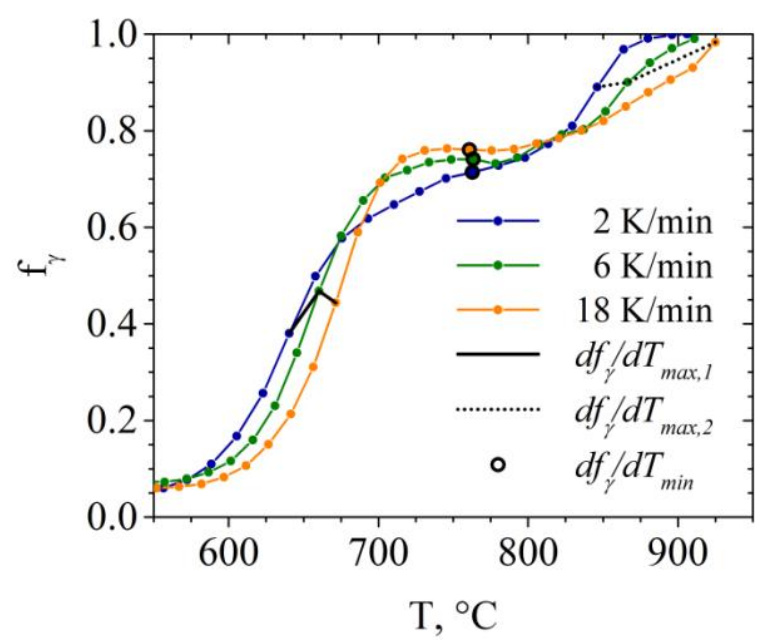

b)

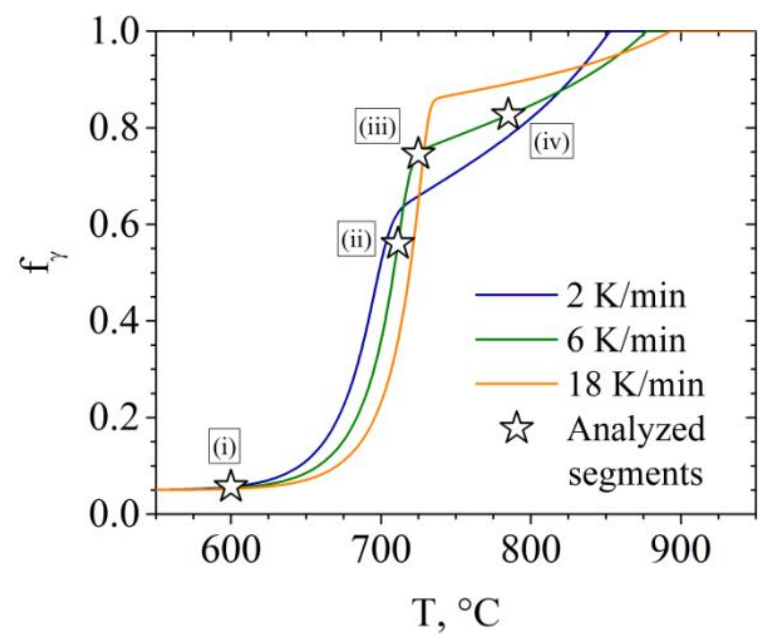

Figure 1: Fraction austenite over temperature for isochronal heating with 2, 6 and $18 \mathrm{~K} \cdot \mathrm{min}^{-1}$ a): followed in-situ with XRD. The maximum and minimum transformation rates are indicated by the broken lines and data points, respectively; b): modeled with kinetics modeling. The analyzed segments in Figure 4 for heating with $6 \mathrm{~K} \cdot \mathrm{min}^{-1}$ are marked with points (i) to (iv).

\subsection{Transmission Kikuchi diffraction}

The microstructure from a dilatometry experiment, in which isochronal heating at 15 K.min- 1 was interrupted at $650{ }^{\circ} \mathrm{C}$, was characterized. The indicated inter-critical annealing treatment was chosen because it promoted the formation of $20 \mathrm{vol} . \%$ thermally stable reversed austenite and was thus ideal to determine a setup of a 
diffusion model, that reflects the microstructure of the in-situ investigation. Figure 2a shows the inverse pole figure map of austenite superimposed to the band-contrast map of martensite. Figure $2 \mathrm{~b}$ shows low-angle grain boundaries (LAGB, $1^{\circ}<\theta<$ $15^{\circ}$ ) and high-angle grain boundaries (HAGB, $\theta>15^{\circ}$ ) of lath martensite colored in green and red, respectively, and the interphase boundaries, which are all HAGBs, colored in white. Not all lath boundaries could be indexed by orientation mapping, since adjacent laths of the same variant in low carbon martensite may have very low misorientation [34-36] and thus fall below the misorientation threshold of $1^{\circ}$. The spacing of austenite lamellae approximately followed the martensite lath spacing and varied for different blocks of martensite, depending on the intersection angle of the specimen surface with the respective microstructure. By measuring the distance of the smallest identified regular austenite lamellae spacings in the different blocks the average lath width was approximated to $250 \mathrm{~nm}$. 
a)

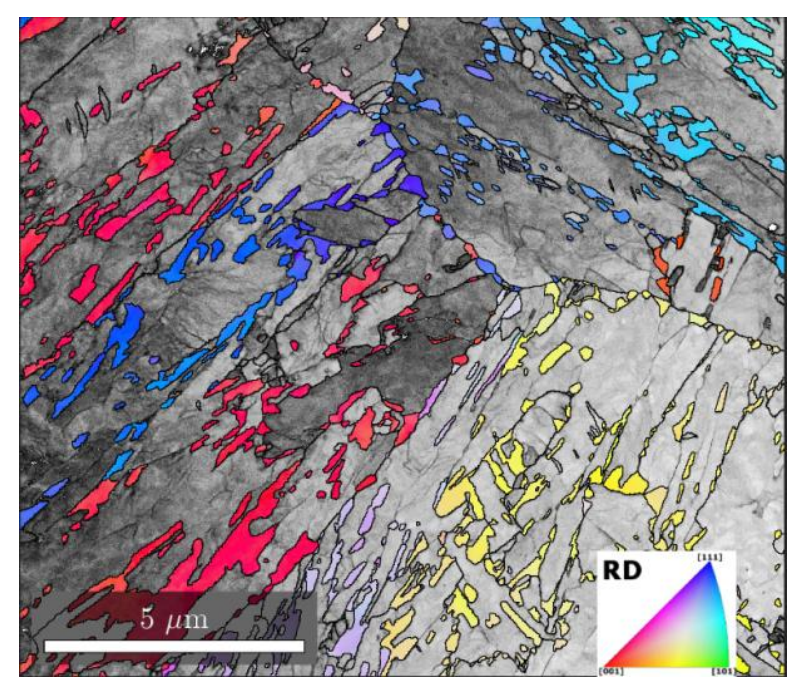

b)

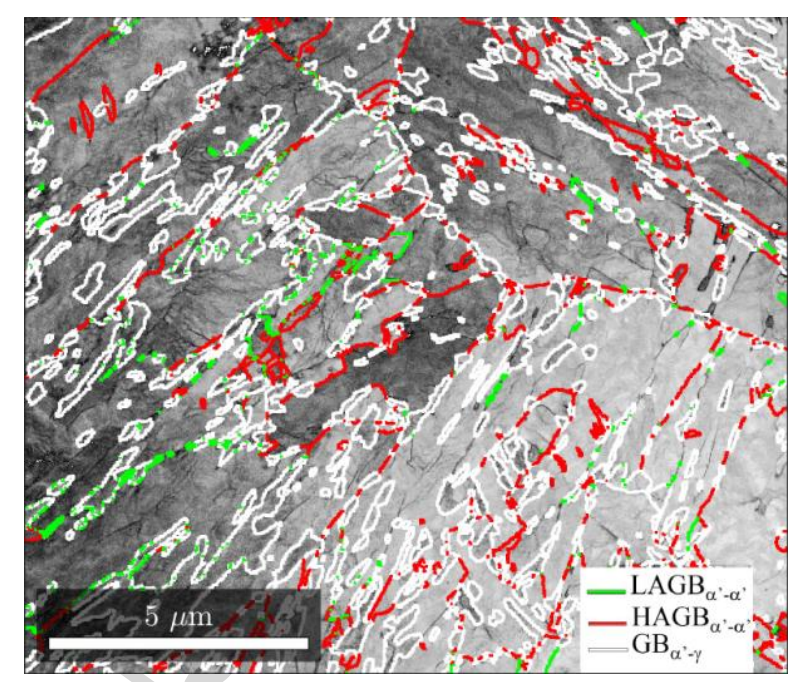

Figure 2: Transmission Kikuchi Diffraction (TKD). a): Inverse Pole Figure

Map of austenite on band-contrast map of martensite for interrupted

heating at $650^{\circ} \mathrm{C}$. Austenite forms on lath boundaries; b): Grain boundary

map. LAGBs $\left(1^{\circ}<\theta<15^{\circ}\right)$ and HAGBs $\left(\theta>15^{\circ}\right)$ in martensite are indicated by green and red coloring, respectively, and inter-phase

boundaries are colored in white.

\section{Kinetics modeling}

In order to elucidate the mechanism responsible for the observed two-step kinetics, the austenitization was modeled with DICTRA, a software package for simulation of diffusion controlled reactions in multi-component alloy systems [37]. In contrast to Kissinger-like methods, which require fitting to an Arrhenius type of transformation and yield effective activation energies for heterogeneous transformations [38], the analysis with kinetics modeling is carried out with direct forward modeling based on 
constitutive equations and the thermodynamics and kinetics databases TCFE6 [39] and MOB2 [40]. Austenitization was modeled using the moving phase-boundary model within DICTRA.

A comprehensive description on the foundation of the DICTRA software is given in Ref. [37]. A short summary of the governing equations is given in the following. Diffusion in DICTRA is modelled based on Fick's second law

$$
\frac{\partial c_{k}}{\partial t}=\frac{\partial}{\partial z}\left(-J_{k}\right)
$$

where $c_{k}$ is the concentration, and $J_{k}$ the flux of component $k$. The flux of component $k$ in a multi-component system with $n$ components is determined by the spatial gradient of the chemical potential $\mu_{i}$ of all components and the proportionality factors $L_{k i}^{\prime}$, which are based on the mobilities of the individual species:

$$
J_{k}=-\sum_{i=1}^{n} L_{k i}^{\prime} \frac{\partial \mu_{i}}{\partial z}
$$

It is noted that the $L_{k i}^{\prime}$ factors are purely kinetic quantities, whereas the chemical potential gradients are purely thermodynamic quantities. The basic data for computation of these parameters are obtained from experimental data and are stored in kinetics and thermodynamics databases, respectively. The composition dependence of the parameters is determined by a Redlich-Kister expansion [41].

In the moving boundary model single-phase regions are separated by an interface, which migrates based on the rate of diffusion to and from the interface. For each time 
step the boundary condition at the phase interface is calculated by assuming local equilibrium and the diffusion problem is solved for each single-phase region. Migration of the interface between two phases $\alpha$ and $\gamma$ is then calculated by solving a flux balance equation for $n-1$ components [42]

$$
v^{\alpha / \gamma}\left(c_{k}^{\alpha}-c_{k}^{\gamma}\right)=J_{k}^{\alpha}-J_{k}^{\gamma}
$$

where $v^{\alpha / \gamma}$ is the interface velocity.

\subsection{Model setup}

Transmission Kikuchi Diffraction (Figure 2) showed that reversed austenite forms on both low- and high-angle boundaries, consistent with results from previous investigations $[8,12-14,43,44]$. Since the spacing of reversed austenite roughly follows the martensite lath spacing, austenitization was modelled by simulation of austenite formation and growth within one martensite lath. The model was thus setup as a 1-dimensional diffusion domain, $d$, which due to symmetry was defined as half the martensite lath width (Figure 3). The domain was discretized to 100 grid-points and set up with zero-flux boundary conditions. In order to show the impact of the martensite lath spacing on the austenitization kinetics, the domain size was varied in a series of additional simulations. The simulation was carried out with a time step of $50 \mathrm{~ms}$ and commenced in a ferrite single phase region, which served as the thermodynamic equivalent of very low carbon lath martensite. For the sake of understanding, the region is referred to as martensite in the analysis of the results. 
Upon isochronal heating the formation of austenite in a planar interface geometry was allowed.

Due to uncertainties of the local distribution of retained austenite in the microstructure, the initial fraction of retained austenite was not taken into consideration in the kinetics model, which only considers reversed austenite formation on lath boundaries. XRD quantitative phase analysis revealed 5 vol. $\%$ of retained austenite in the initial microstructure and EBSD analysis revealed that some of the retained austenite was present in inhomogeneously distributed chunky morphology [45]. Thus, the initial amount of chunky retained austenite was represented as a fixed value in the transformation curves (Figure 1b), and the remaining fraction was determined by the simulated formation of austenite from a martensite lath.

The moving phase boundary model in DICTRA is based on the formation and evolution of a single grain of austenite and does not include a classic nucleation model. Other models, as the Thermo-Calc precipitation module [46], are available and well suited for analyzing nucleation and competitive growth, but do not treat the diffusion controlled evolution of two phases, which is the purpose of this investigation. DICTRA does however allow for input of a critical driving force for precipitation of austenite, which makes it possible to account for a nucleation barrier. Since the nucleation mechanism of reversed austenite has not been determined unequivocally by experimental means (see general discussion section), the model was 
generally set up without considering such a nucleation barrier. For the sake of discussing the potential effect of a nucleation barrier on the kinetics of austenitization, additional simulations with nucleation barriers of 50 and $100 \mathrm{~J}^{\mathrm{mol}}{ }^{-1}$ were carried out.

An additional series of simulations was run with enhancement of the mobilities of $\mathrm{Ni}$ and $\mathrm{Cr}$ in $b c c$ and $f c c$ by a factor of 10 . This was done in an attempt to identify the rate-determining mechanisms at different stages of the transformation in the multicomponent diffusion system.

Simulations were performed for different heating rates to investigate whether the presented approach yielded results, which are consistent with the experimental data. The system was limited to $\mathrm{Fe}, \mathrm{Cr}$ and $\mathrm{Ni}$ to increase numerical stability.

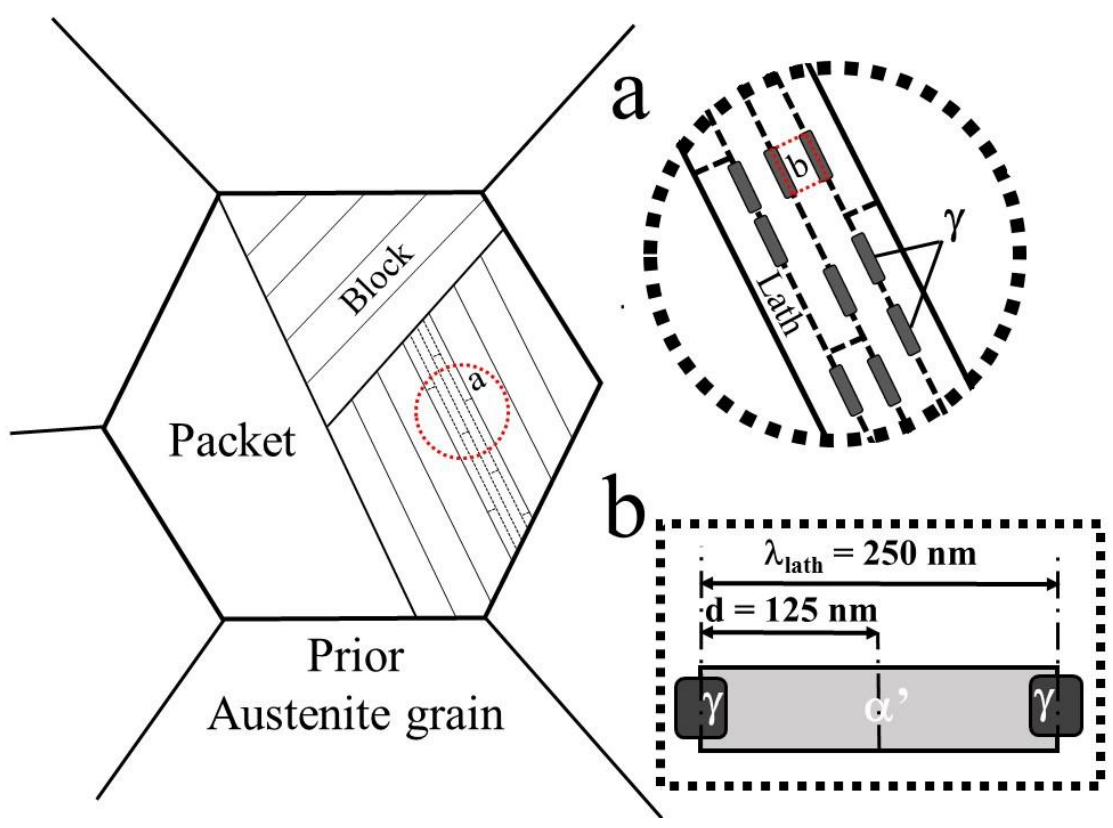

Figure 3: Schematic hierarchy of lath martensite. Inset $a$ shows the lath structure in a block and indicates the nucleation sites of lamellar austenite $(\gamma)$ at 
lath boundaries. Inset $b$ shows the symmetry of a single lath with the lath width $\lambda_{\text {lath }}$ and the resulting domain size $d$ used in the one-dimensional kinetics model.

\subsection{Results and interpretation}

Kinetics modeling predicted for all heating rates an effective start temperature of the transformation, i.e. a temperature at which the transformation rate is discernable within the range of experimental measurement accuracy, at approx. $575{ }^{\circ} \mathrm{C}$ (Figure 1b). This is in close agreement with the results obtained from XRD (Figure 1a). On continued heating the transformation curves were offset by approx. $45{ }^{\circ} \mathrm{C}$ as compared to the experimental data. The model consistently predicts a shift in maximum transformation rate to higher temperature and an increase in the temperature where deceleration in the first stage occurs. Moreover, the extent of the deceleration of austenitization and the completion of the second stage of austenitization are predicted consistently with the trends observed in the experimental data.

Four distinct segments could be identified in the predicted martensite-toaustenite transformation curves. Those segments are (i) Nucleation, (ii) Maximum growth rate in stage 1, (iii) Deceleration, and (iv) Onset of growth in stage 2, which are indicated by four points in Figure 1b. In order to analyze the governing mechanisms for these characteristic segments in the kinetics of the transformation, the diffusion profiles of $\mathrm{Cr}$ and $\mathrm{Ni}$ were analyzed for heating with $6 \mathrm{~K} \cdot \mathrm{min}^{-1}$, representing all heating rates, at the corresponding temperatures (Figure 4). A 
simulation of the evolution of the composition profiles with time is available as supplementary material (Video 1, Video 2 and Video 3 show austenitization at 2, 6 and $18 \mathrm{~K} \cdot \mathrm{min}^{-1}$, respectively). Evidently, the experimentally determined two-stage austenitization could be reproduced by the kinetics model, thus analysis of the four characteristic segments can be used to explain the governing mechanisms involved.

\section{(i) Nucleation and initial growth}

Diffusion profile (i) shows austenite growing from the left-hand side of the diffusion domain immediately after nucleation (Figure 4). The segment appears at approx. 623, 635 and $647{ }^{\circ} \mathrm{C}$ for heating with 2, 6, and $18 \mathrm{~K} \cdot \mathrm{min}^{-1}$ (Figure 1b). According to the model, considerable partitioning of $\mathrm{Ni}$ and some depletion in $\mathrm{Cr}$ occurs at the nucleation and initial growth stage of austenite at these temperatures. 


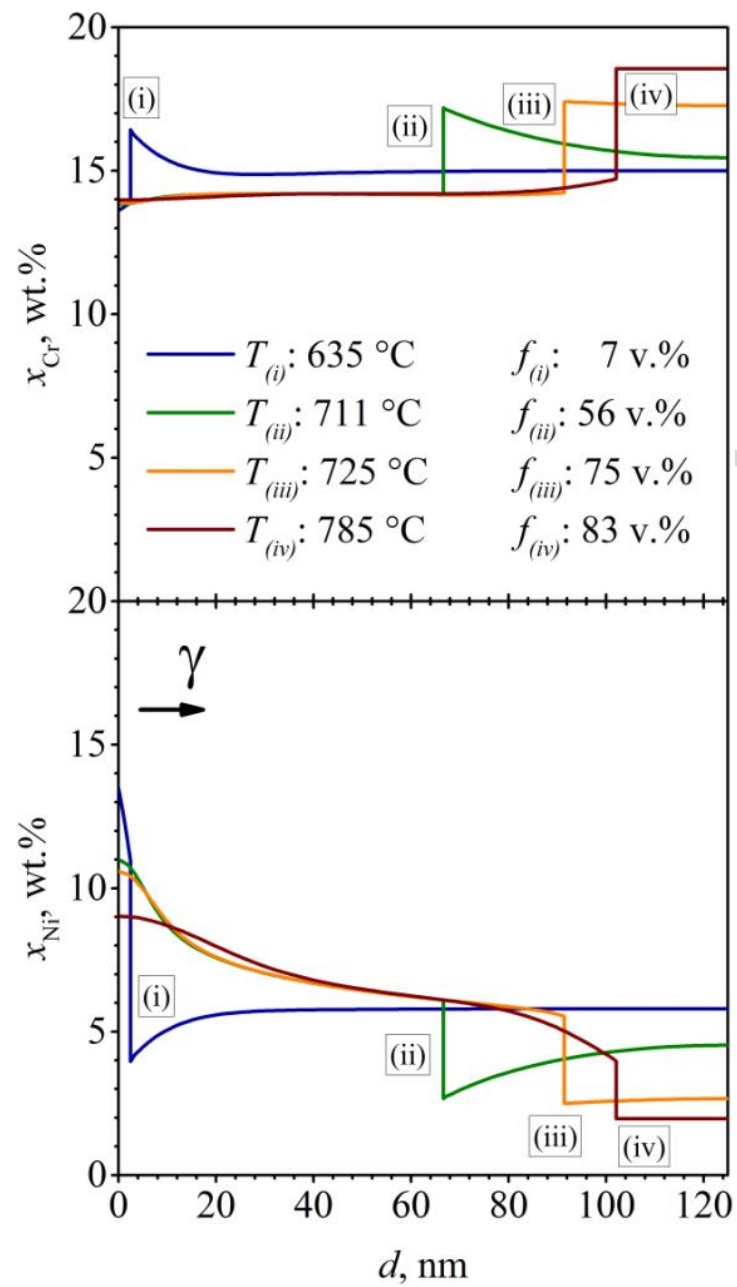

Figure 4: Ni and Cr content vs. distance $d$ as indicated in Figure 3 for heating with $6 \mathrm{~K} \cdot \mathrm{min}^{-1}$ for the four distinct segments of transformation indicated by the points in Figure 1b. Austenite grows from the left-hand side of the domain and the austenite/martensite interface is represented by the discontinuity in the profiles (i.e. vertical lines).

\section{(ii) Growth in stage 1}

Diffusion profile (ii) shows the $\mathrm{Ni}$ and $\mathrm{Cr}$ content at the maximum rate of transformation in the first stage of austenitization (Figure 4). The segment appears at 695,711 and $726^{\circ} \mathrm{C}$ for the heating rates 2, 6, and $18 \mathrm{~K} \cdot \mathrm{min}^{-1}$ (Figure 1b). Martensite 
is locally depleted in $\mathrm{Ni}$ at the interface, but provides excess $\mathrm{Ni}$ from the bulk to maintain the transformation. The transformation is at its maximum rate, enabled by increasing driving force for formation of austenite and increasing diffusivities with increasing temperature. The predicted transformation rates in this segment are in good agreement with the measured transformation rates (Figure 1). The austenitization kinetics under individual enhancement of the mobilities of $\mathrm{Ni}$ and $\mathrm{Cr}$ in $f c c$ and $b c c$ by a factor of 10 for heating with $6 \mathrm{~K} \cdot \mathrm{min}^{-1}$ is shown in Figure 5. In particular a change in the mobility of $\mathrm{Ni}$ in $b c c$ affects the kinetics (and the deceleration) in the first stage of austenitization, while the other mobilities appear to have a minor or negligible influence in this stage. These effects support the interpretation that $\mathrm{Ni}$ diffusion in $b c c$ is rate determining in the first stage of austenitization.

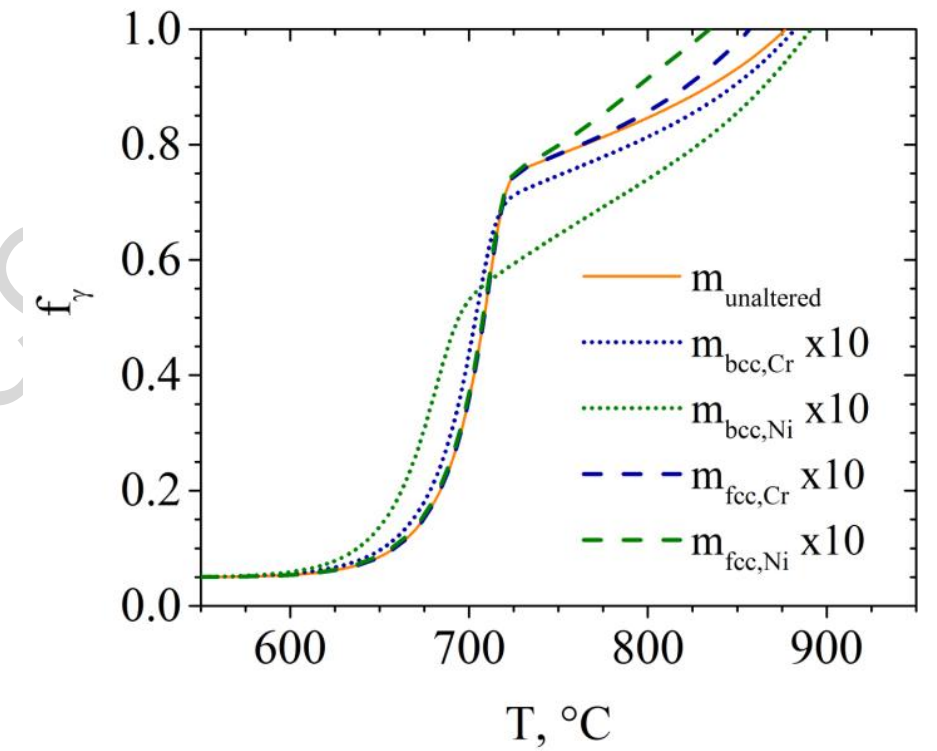

Figure 5: Kinetics modeling of austenitization with 6 K.min ${ }^{-1}$ showing the 
effect of individually enhancing the mobility for $\mathrm{Ni}$ and $\mathrm{Cr}$ in $f c c$ and $b c c$ by the factor 10; diffusion of $\mathrm{Ni}$ in $b c c$ and $\mathrm{Ni}$ in $f c c$ have the strongest effect on the kinetics in stage 1 and 2, respectively.

\section{(iii) Deceleration of the transformation kinetics}

Diffusion profile (iii) shows the contents of $\mathrm{Ni}$ and $\mathrm{Cr}$, at which deceleration of the transformation occurs. This segment appears at 713,725 , and $736{ }^{\circ} \mathrm{C}$ for the heating rates 2,6 , and $18 \mathrm{~K} \cdot \mathrm{min}^{-1}$, respectively (Figure $1 \mathrm{~b}$ ). It is evident that the transformation is halted because impingement of the diffusion field with the model boundary causes the gradients in $\mathrm{Ni}$ and $\mathrm{Cr}$ content in martensite virtually to vanish. In the actual microstructure this mechanism corresponds to the situation in which the diffusion field of the simulated austenite particle starts to overlap with the diffusion field of the adjacent austenite particle (see inset $b$ in Figure 3). Then, continued growth of the austenite phase fraction is mainly achieved by a change of Ni profile in austenite close to the interface with martensite, while some redistribution of $\mathrm{Ni}$ in $f c c$ commences (compare profiles (iii) and (iv) in Figure 4). Soft impingement in martensite occurred at higher phase fractions for higher heating rates (Figure 1b). The predictions of the phase fractions and temperatures where soft impingement occurs are in fair agreement with the onsets of the plateaus of the experimental transformation curves (Figure 1a). 


\section{(iv) Growth in stage 2}

Diffusion profile (iv) corresponds to the $\mathrm{Ni}$ and $\mathrm{Cr}$ distribution at the onset of the second stage of austenitization (Figure 4). The segment appears at approx. 770, 785 and $821^{\circ} \mathrm{C}$ for the heating rates 2,6 , and $18 \mathrm{~K} \cdot \mathrm{min}^{-1}$ (Figure $1 \mathrm{~b}$ ). The strong increase in the gradient in the $\mathrm{Ni}$ content in austenite close to the interface with martensite on proceeding from (iii) to (iv), establishes a larger driving force for Ni-diffusion and, hence, Ni-redistribution in austenite. As the content of $\mathrm{Cr}$ in $f c c$ changes only slightly, diffusion of $\mathrm{Ni}$ in $f c c$ austenite appears to be rate-determining for the second stage of austenitization. The austenitization kinetics under individual enhancement of the mobilities in Figure 5 confirms that in particular a change of the mobility of $\mathrm{Ni}$ in $f c c$ affects the duration of the deceleration and the kinetics in the second stage of austenitization. This is consistent with Ni diffusion in $f c c$ as rate-determining for the overall kinetics in stage 2 of the austenitization.

\section{Effect of domain size and nucleation barrier}

Figure $6 \mathrm{a}$ shows the predicted austenitization by the kinetics model for heating with $6 \mathrm{~K} \cdot \mathrm{min}^{-1}$ considering domain sizes of 75,125 and $175 \mathrm{~nm}$, corresponding to lath widths of 150,250 and $350 \mathrm{~nm}$, respectively. By altering the lath width, the diffusion distance until soft impingement is directly affected (inset $b$ in Figure 3). Comparison of Figure 6a with Figure $1 \mathrm{~b}$ demonstrates that an increase in domain size corresponds to decreasing the heating rate, i.e. increasing the diffusion time. 
Figure $6 \mathrm{~b}$ compares austenitization with $6 \mathrm{~K} \cdot \mathrm{min}^{-1}$ without nucleation barrier with austenitization considering nucleation barriers of 50 and $100 \mathrm{~J} \cdot \mathrm{mol}^{-1}$. It is evident that inclusion of the barriers led to superheating of 19 and $45{ }^{\circ} \mathrm{C}$, respectively, before nucleation occurred. The spikes in the transformation curves are a numerical artefact, caused by fluctuations in determining the starting value for the interface position and velocity in DICTRA. The fraction of austenite is initially insignificantly higher for transformations with nucleation barrier, but levels with the transformation without nucleation barrier after heating of approx. $100{ }^{\circ} \mathrm{C}$ (see inset in Figure 6b).

a)

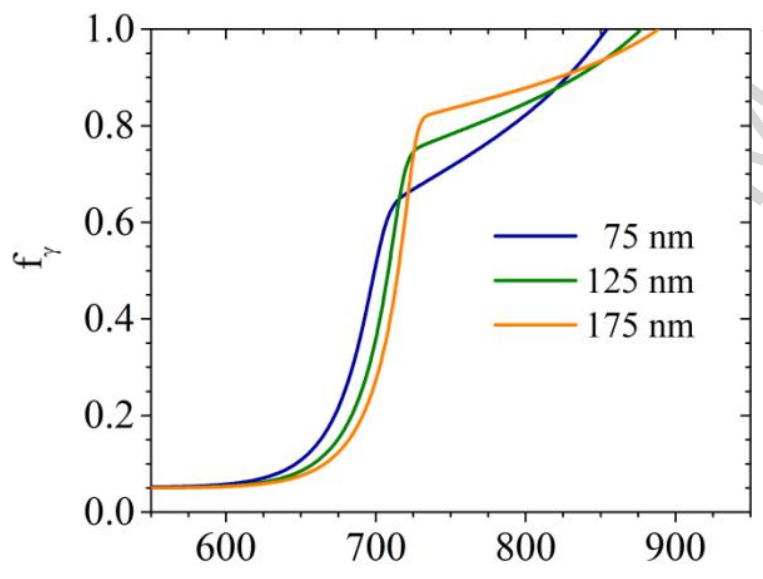

$\mathrm{T},{ }^{\circ} \mathrm{C}$ b)

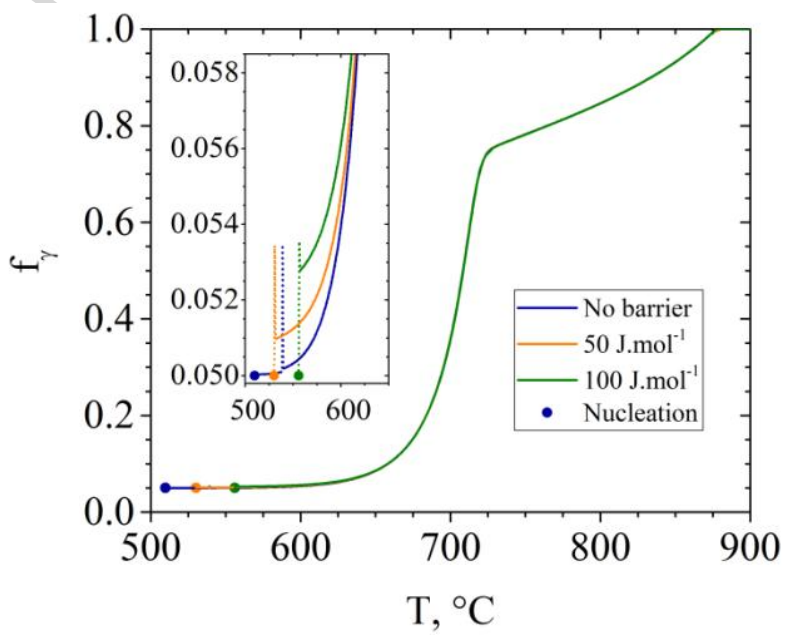


Figure 6a): Prediction of austenitization with $6 \mathrm{~K} \cdot \mathrm{min}^{-1}$ by kinetics modeling with different domain sizes, i.e. considering different martensite lath widths; Figure 6b): Simulation of austenitization with 6 K.min ${ }^{-1}$ with nucleation barriers of 50 and $100{\mathrm{~J} . \mathrm{mol}^{-1}}^{\text {compared to }}$ simulation without nucleation barrier. The data points indicate nucleation and the broken lines discontinuities from a numerical artefact. The effect of the nucleation barrier is only apparent from the magnification displayed in the inset.

\section{General discussion}

\subsection{Governing mechanisms}

The rate-determining mechanism for the first stage of austenitization was identified as diffusion of $\mathrm{Ni}$ in $b c c$. This result is in line with the interpretation by Bojack et al., who suggested that the first stage of austenite formation would mainly be due to partitioning of $\mathrm{Ni}$ and $\mathrm{Mn}$, leaving martensite partially untransformed [22].

Bojack et al. suggested that the second stage of transformation would be governed by increased diffusivity of $\mathrm{Ni}$ and $\mathrm{Mn}$ at higher temperatures together with the decomposition of carbides and nitrides [22]. The current investigation strongly indicates that diffusion of $\mathrm{Ni}$ in $f c c$ after soft impingement in martensite governs the kinetics of the transformation in the second stage. Since the interstitial element content in the present alloy is very low (cf. Table 1), the dissolution of carbides and nitrides is expected to play a negligible role in the transformation. 


\subsection{Quantitative fit of experimental and modeled data}

Evidently, the model succeeds in yielding a good qualitative fit to the experimentally assessed austenitization kinetics and in identifying the governing mechanisms. Quantitatively the model gives a reasonable fit, but predicts the initial growth stage to occur at higher temperatures and the soft impingement at higher phase fractions. These deviations are ascribed to simplifications in the model, which are intentional as not to obscure the effects of the main mechanisms involved in the transformation. The following additions are expected to provide a further improvement of the accuracy of the model predictions:

- It is still unclear whether austenite nucleates or, rather, grows from thin layers of inter-lath retained austenite. The dispute revolves around the austenite memory effect, which describes the inheritance of the orientation of reversed austenite from prior austenite grains. The orientation inheritance could indicate a variant selection mechanism [12] or growth from inter-lath retained austenite $[13,47]$. In the prior case, grain-boundaries are potentially decorated by solute from grain boundary segregation prior to the nucleation of austenite [48]. In the latter case, substantial diffusion towards retained austenite could activate the growth. Regardless of the actual mechanism it is expected that an enrichment in solute would enable premature formation of reversed austenite.

- It is anticipated that the driving force for the nucleation of austenite is increased by the release of residual stresses from metastable lath martensite [49]. 
- A high dislocation density in lath martensite is likely to enable pipe diffusion and could thus lead to a lower activation energy of the atom mobilities. This would lead to faster diffusion kinetics at the onset of the transformation, and a decay of the pipe diffusion contribution with annihilation of dislocations at higher temperature [50]. Preliminary attempts on including the effect of a temperature dependent dislocation density on the mobility data in the kinetics model, using dislocation density data from Ref. [50] and the grain-boundary model in DICTRA, indeed led to an improved correspondence between simulated and experimental results. However, for the present system reliable input data on the evolution of the dislocation density with temperature is currently lacking and demands more experimental work. A first idea of how the contribution of the dislocation density would affect the austenitization kinetics can be obtained from the graphs on enhanced mobility in $b c c$ in Figure 5.

All of these omissions, when implemented, would increase the initial growth rate of austenite, increase the partitioning and thus lead to soft impingement at lower phase fractions, thus accounting for the overestimation of the phase fraction where soft impingement occurs in the simulations in Fig. $1 \mathrm{~b}$.

\subsection{Effect of heating rate, domain size and nucleation barrier}

The four described segments, which govern the austenitization kinetics, were identified for all analyzed heating rates, even for heating at $100 \mathrm{~K} \cdot \mathrm{min}^{-1}$. The effect of changing the domain size on the transformation kinetics correlated with the effect of 
changing the heating rate (Figure 6a). Generally, the transformation kinetics depended on the ratio of available diffusion time and diffusion distance.

It was evident that the nucleation barrier did not affect the overall two-step kinetics strongly. Figure $6 \mathrm{~b}$ shows that transformation with nucleation barrier leads to an increased fraction of austenite compared to the transformation without barrier just after nucleation, and that this divergence fades away on continued heating. This might seem counterintuitive, but is caused by less partitioning during formation of austenite at slightly more elevated temperatures. Thus, more austenite can be formed instantly at nucleation. Since the concentration gradient in austenite during heating is subject to homogenization, this marginal initial difference disappears upon further heating. Ultimately the time and temperature interval spent from nucleation to diffusion-controlled growth for the two-step kinetics is sufficiently large that the overall kinetics are not strongly affected by the nucleation mechanism.

\section{Conclusions}

The conclusions of the in-situ observation of two-stage austenitization and the modeling of austenitization with the kinetics model DICTRA are:

- Austenitization of X4CrNiMo16-5-1 super martensitic stainless steel during isochronal heating at $2-18 \mathrm{~K} \cdot \mathrm{min}^{-1}$ occurs in two stages.

- Two-stage austenitization kinetics are predicted from kinetics modeling of multi-component diffusion in DICTRA based on the transformation of a single martensite lath to austenite and nucleation without nucleation barrier. 
- The mechanism for the deceleration of the transformation after the first stage is identified as soft impingement in the martensite phase.

- Ni-diffusion in the $b c c$ lattice is rate-determining for the first stage of austenitization, where Ni diffuses from martensite towards the phase-interface.

- Ni-diffusion in the $f c c$ lattice is rate-determining for the second stage of austenitization, where austenite, which is heavily enriched in $\mathrm{Ni}$ due to partitioning in the initial growth stage, is required to homogenize in order to supply solute to the phase-interface. This requires the build-up of a concentration gradient.

- The martensite lath width, corresponding to two times the diffusion distance in the model, has a similar effect on the austenitization kinetics as the heating rate.

\section{Acknowledgement}

D. Apel, C. Genzel, M. Klaus and G. Wagener, Helmholtz Zentrum für Materialien und Energie (HZME), are acknowledged for their support during in-situ experiments at the Berlin synchrotron facility HZB-BESSY II. The Danish Underground Consortium is gratefully acknowledged for financial support to the Danish Hydrocarbon Research Center (DHRTC). M. Villa acknowledges the Danish Council for Independent Research (G.R. grant: DFF-4005-00223) for financial support. 


\section{References}

[1] P. Toussaint, J.-J. Dufrane, Advances in the making and base material properties of supermartensitic stainless steels (SMSS), in: Supermartensitic Stainl. Steels 2002 Brussels, KCI Publishing, 2002: pp. 23-27.

[2] A.W. Marshall, J.C.M. Farrar, Welding of Ferritic and Martensitic 11-14\% Cr Steels, Weld. World. 45 (2001) 19-42.

[3] L.M. Smith, M. Celant, Martensitic stainless steel flowlines - Do they pay?, in: Supermartensitic Stainl. Steels 1999, 1999: pp. 66-73.

[4] D.-S. Leem, Y.-D. Lee, J.-H. Jun, C.-S. Choi, Amount of retained austenite at room temperature after reverse transformation of martensite to austenite in an Fe-13\%Cr-7\%Ni-3\%Si martensitic stainless steel, Scr. Mater. 45 (2001) 767772. doi:10.1016/S1359-6462(01)01093-4.

[5] H.J. Niederau, A New Low-Carbon 16Cr-5Ni Stainless Martensitic Cast Steel, in: G. Behal, A.S. Melilli (Eds.), Stainl. Steel Cast., ASTM, Bal Harbour, Florida, 1982: pp. 382-393.

[6] M. Al Dawood, I.S. El Mahallawi, M.E. Abd El Azim, M.R. El Koussy, Thermal aging of $16 \mathrm{Cr}-5 \mathrm{Ni}-1 \mathrm{Mo}$ stainless steel Part $1-$ Microstructural analysis, Mater. Sci. Technol. $20 \quad$ (2004) 363-369. doi:10.1179/026708304225011135.

[7] D. Ye, J. Li, W. Jiang, J. Su, K. Zhao, Effect of $\mathrm{Cu}$ addition on microstructure and mechanical properties of $15 \% \mathrm{Cr}$ super martensitic stainless steel, Mater. 
Des. 41 (2012) 16-22. doi:10.1016/j.matdes.2012.04.036.

[8] P.D. Bilmes, M. Solari, C.. Llorente, Characteristics and effects of austenite resulting from tempering of $13 \mathrm{Cr}-\mathrm{NiMo}$ martensitic steel weld metals, Mater. Charact. 46 (2001) 285-296. doi:10.1016/S1044-5803(00)00099-1.

[9] M. Karlsen, J. Hjelen, Ø. Grong, G. Rørvik, R. Chiron, U. Schubert, et al., SEM/EBSD based in situ studies of deformation induced phase transformations in supermartensitic stainless steels, Mater. Sci. Technol. 24 (2008) 64-72. doi:10.1179/174328407X245797.

[10] S. Zhang, P. Wang, D. Li, Y. Li, Investigation of the evolution of retained austenite in $\mathrm{Fe}-13 \% \mathrm{Cr}-4 \% \mathrm{Ni}$ martensitic stainless steel during intercritical tempering, Mater. Des. 84 (2015) 385-394. doi:10.1016/j.matdes.2015.06.143.

[11] T. LeBrun, T. Nakamoto, K. Horikawa, H. Kobayashi, Effect of retained austenite on subsequent thermal processing and resultant mechanical properties of selective laser melted 17-4 PH stainless steel, Mater. Des. 81 (2015) 44-53. doi:10.1016/j.matdes.2015.05.026.

[12] N. Nakada, T. Tsuchiyama, S. Takaki, S. Hashizume, Variant Selection of Reversed Austenite in Lath Martensite, ISIJ Int. 47 (2007) 1527-1532. doi:10.2355/isijinternational.47.1527.

[13] L. Liu, Z.-G. Yang, C. Zhang, Effect of retained austenite on austenite memory of a 13\% Cr-5\% Ni martensitic steel, J. Alloys Compd. 577 (2013) 654-660. doi:10.1016/j.jallcom.2012.04.021. 
[14] N. Nakada, T. Tsuchiyama, S. Takaki, N. Miyano, Temperature Dependence of Austenite Nucleation Behavior from Lath Martensite, ISIJ Int. 51 (2011) 299304. doi:10.2355/isijinternational.51.299.

[15] Y.Y. Song, X.Y. Li, L.J. Rong, Y.Y. Li, T. Nagai, Reversed austenite in 0Cr13Ni4Mo martensitic stainless steels, Mater. Chem. Phys. 143 (2014) 728734. doi:10.1016/j.matchemphys.2013.10.006.

[16] L. Yuan, D. Ponge, J. Wittig, P. Choi, J.A. Jiménez, D. Raabe, Nanoscale austenite reversion through partitioning, segregation and kinetic freezing: Example of a ductile 2 GPa Fe-Cr-C steel, Acta Mater. 60 (2012) 2790-2804. doi:10.1016/j.actamat.2012.01.045.

[17] Y. Song, X. Li, L. Rong, Y. Li, Anomalous Phase Transformation from Martensite to Austenite in Fe-13\%Cr-4\%Ni-Mo Martensitic Stainless Steel, J. Mater. Sci. Technol. 26 (2010) 823-826. doi:10.1016/S1005-0302(10)60131-4.

[18] Y.-K. Lee, H.-C. Shin, D.-S. Leem, J.-Y. Choi, W. Jin, C.-S. Choi, Reverse transformation mechanism of martensite to austenite and amount of retained austenite after reverse transformation in $\mathrm{Fe}-3 \mathrm{Si}-13 \mathrm{Cr}-7 \mathrm{Ni}$ (wt-\%) martensitic $\begin{array}{lllllll}\text { stainless steel, } & \text { Mater. } & \text { Sci. } & \text { Technol. } & 19 & \text { (2003) 393-398. }\end{array}$ doi:10.1179/026708303225009742.

[19] W. Jiang, D. Ye, J. Li, J. Su, K. Zhao, Reverse Transformation Mechanism of Martensite to Austenite in 00Cr15Ni7Mo2WCu2 Super Martensitic Stainless Steel, Steel Res. Int. 85 (2014) 1150-1157. doi:10.1002/srin.201300264. 
[20] W. Jiang, K. Zhao, D. Ye, J. Li, Z. Li, J. Su, Effect of Heat Treatment on Reversed Austenite in Cr15 Super Martensitic Stainless Steel, J. Iron Steel Res. Int. 20 (2013) 61-65. doi:10.1016/S1006-706X(13)60099-0.

[21] V.A. Esin, B. Denand, Q. Le Bihan, M. Dehmas, J. Teixeira, G. Geandier, et al., In situ synchrotron X-ray diffraction and dilatometric study of austenite formation in a multi-component steel: Influence of initial microstructure and heating rate, Acta Mater. $80 \quad$ (2014) 118-131. doi:10.1016/j.actamat.2014.07.042.

[22] A. Bojack, L. Zhao, P.F. Morris, J. Sietsma, Austenite Formation from Martensite in a 13Cr6Ni2Mo Supermartensitic Stainless Steel, Metall. Mater. Trans. A. 47 (2016) 1996-2009. doi:10.1007/s11661-016-3404-z.

[23] A. Bojack, L. Zhao, P.F. Morris, J. Sietsma, In-situ determination of austenite and martensite formation in $13 \mathrm{Cr} 6 \mathrm{Ni} 2 \mathrm{Mo}$ supermartensitic stainless steel, Mater. Charact. 71 (2012) 77-86. doi:10.1016/j.matchar.2012.06.004.

[24] R. Kapoor, I.S. Batra, On the $\alpha$ to $\gamma$ transformation in maraging (grade 350), PH 13-8 Mo and 17-4 PH steels, Mater. Sci. Eng. A. 371 (2004) 324-334. doi:10.1016/j.msea.2003.12.023.

[25] D. San Martín, P.E.J. Rivera-Díaz-del-Castillo, C. García-de-Andrés, In situ study of austenite formation by dilatometry in a low carbon microalloyed steel, Scr. Mater. 58 (2008) 926-929. doi:10.1016/j.scriptamat.2008.01.019.

[26] C. Servant, P. Lacombe, Structural transformations produced during tempering 
of Fe-Ni-Co-Mo alloys, J. Mater. Sci. 12 (1977) 1807-1826. doi:10.1007/BF00566241.

[27] C. Servant, G. Maeder, I. Introduction, C. De Recherches, L. De Mrtal-, O. Cedex, et al., Investigation Into the Effect of Substituting, 10 (1979).

[28] F. Niessen, M. Villa, D. Apel, O. Keßler, M. Reich, J. Hald, et al., In situ techniques for the investigation of the kinetics of austenitization of supermartensitic stainless steel, Mater. Sci. Forum. 879 (2017) 1381-1386. doi:10.4028/www.scientific.net/MSF.879.1381.

[29] E.I. Galindo-Nava, W.M. Rainforth, P.E.J. Rivera-Díaz-del-Castillo, Predicting microstructure and strength of maraging steels: Elemental optimisation, Acta Mater. 117 (2016) 270-285. doi:10.1016/j.actamat.2016.07.020.

[30] C. Genzel, I. a. Denks, M. Klaus, The Materials Science Beamline EDDI for Energy-Dispersive Analysis of Subsurface Residual Stress Gradients, Mater. $\begin{array}{llll}\text { Sci. } & \text { Forum. } & \text { 524-525 }\end{array}$ doi:10.4028/www.scientific.net/MSF.524-525.193.

[31] B.C. Giessen, G.E. Gordon, X-ray Diffraction: New High-Speed Technique Based on X-ray Spectrography, Sci. New Ser. 159 (1968) 973-975. doi:10.1038/020493a0.

[32] E.S.U. Laine, A high-speed determination of the volume fraction of ferrite in austenitic stainless steel by EDXRD, J. Phys. F Met. Phys. 8 (2001) 1343-1348. doi:10.1088/0305-4608/8/7/007. 
[33] R. Hielscher, H. Schaeben, A novel pole figure inversion method: Specification of the MTEX algorithm, J. Appl. Crystallogr. 41 (2008) 1024-1037. doi:10.1107/S0021889808030112.

[34] B.P.J. Sandvik, C.M. Wayman, Characteristics of Lath Martensite: Part I. Crystallographic and Substructural Features, Metall. Trans. A. 14 (1983) 809822. doi:10.1007/BF02644284.

[35] S. Morito, H. Tanaka, R. Konishi, T. Furuhara, T. Maki, The morphology and crystallography of lath martensite in Fe-C alloys, Acta Mater. 51 (2003) 17891799. doi:10.1016/j.actamat.2006.07.009.

[36] S. Morito, X. Huang, T. Furuhara, T. Maki, N. Hansen, The morphology and crystallography of lath martensite in alloy steels, Acta Mater. 54 (2006) 53235331. doi:10.1016/j.actamat.2006.07.009.

[37] A. Borgenstam, A. Engström, L. Höglund, J. Ågren, DICTRA, a tool for simulation of diffusional transformations in alloys, J. Phase Equilibria. 21 (2000) 269-280. doi:10.1361/105497100770340057.

[38] E.J. Mittemeijer, Review - Analysis of the kinetics of phase transformations, J. Mater. Sci. 27 (1992) 3977-3987. doi:10.1007/BF01105093.

[39] Thermo-Calc Software TCFE6 Steels/Fe-alloys database version 6.2 (accessed November 2009), (n.d.).

[40] Thermo-Calc Software TCS Alloys Mobility Database MOB2 (accessed 08 April 1998), (n.d.). 
[41] O. Redlich, A.T. Kister, Algebraic Representation of Thermodynamic Properties and the Classification of Solutions, Ind. Eng. Chem. 40 (1948) 345348. doi:10.1021/ie50458a036.

[42] H. Larsson, A model for 1D multiphase moving phase boundary simulations under local equilibrium conditions, Calphad Comput. Coupling Phase Diagrams Thermochem. 47 (2014) 1-8. doi:10.1016/j.calphad.2014.06.001.

[43] Y. Song, D.H. Ping, F.X. Yin, X.Y. Li, Y.Y. Li, Microstructural evolution and low temperature impact toughness of a $\mathrm{Fe}-13 \% \mathrm{Cr}-4 \% \mathrm{Ni}-\mathrm{Mo}$ martensitic stainless steel, Mater. Sci. Eng. A. 527 (2010) 614-618. doi:10.1016/j.msea.2009.08.022.

[44] C. Servant, E.H. Gherbi, G. Cizeron, TEM investigation of the tempering behaviour of the maraging PH 17.4 Mo stainless steel, J. Mater. Sci. 22 (1987) $2297-2304$.

[45] F. Niessen, Technical University of Denmark (DTU); Danish Hydrocarbon Research and Technology Centre; 2800 Kgs. Lyngby; Denmark, Unpubl. Res. (2016).

[46] The Precipitation Module (TC-PRISMA) User Guide 2016a, (accessed 23 July2016), (n.d.).

[47] L. Liu, Z.G. Yang, C. Zhang, W.B. Liu, An in situ study on austenite memory and austenitic spontaneous recrystallization of a martensitic steel, Mater. Sci. Eng. A. 527 (2010) 7204-7209. doi:10.1016/j.msea.2010.07.083. 
[48] D. Raabe, S. Sandlöbes, J. Millán, D. Ponge, H. Assadi, M. Herbig, et al., Segregation engineering enables nanoscale martensite to austenite phase transformation at grain boundaries: A pathway to ductile martensite, Acta Mater. 61 (2013) 6132-6152. doi:10.1016/j.actamat.2013.06.055.

[49] M. Villa, F. Niessen, M.A.J. Somers, In situ investigation of the evolution of lattice strain and stresses in austenite and martensite during quenching and tempering of steel, In preparation, (2016).

[50] Z.M. Shi, W. Gong, Y. Tomota, S. Harjo, J. Li, B. Chi, et al., Study of tempering behavior of lath martensite using in situ neutron diffraction, Mater. Charact. 107 (2015) 29-32. doi:10.1016/j.matchar.2015.06.040. 


\section{Figure captions}

Figure 1: Fraction austenite over temperature for isochronal heating with 2, 6 and 18 K.min ${ }^{-1}$ a): followed in-situ with XRD. The maximum and minimum transformation rates are indicated by the broken lines and data points, respectively; b): modeled with kinetics modeling. The analyzed segments in Figure 4 for heating with $6 \mathrm{~K} \cdot \mathrm{min}^{-1}$ are marked with points (i) to (iv).

Figure 2: Transmission Kikuchi Diffraction (TKD); a): Inverse Pole Figure Map of austenite on band-contrast map of martensite for interrupted heating at $650{ }^{\circ} \mathrm{C}$. Austenite forms on lath boundaries; b): Grain boundary map. LAGBs $\left(1^{\circ}<\theta<15^{\circ}\right)$ and HAGBs $\left(\theta>15^{\circ}\right)$ in martensite are indicated by green and red coloring, respectively, and inter-phase boundaries are colored in white.

Figure 3: Schematic hierarchy of lath martensite. Inset a shows the lath structure in a block and indicates the nucleation sites of lamellar austenite $(\gamma)$ at lath boundaries. Inset $b$ shows the symmetry of a single lath with the lath width $\lambda$ lath and the resulting domain size $\mathrm{d}$ used in the one-dimensional kinetics model.

Figure 4: $\mathrm{Ni}$ and $\mathrm{Cr}$ content vs. distance $\mathrm{d}$ as indicated in Figure 3 for heating with 6 K.min-1 for the four distinct segments of transformation indicated by the points in Figure 1b. Austenite grows from the left-hand side of the domain and the austenite/martensite interface is represented by the discontinuity in the profiles (i.e. vertical lines).

Figure 5: Kinetics modeling of austenitization with 6 K.min-1 showing the effect of individually enhancing the mobility for $\mathrm{Ni}$ and $\mathrm{Cr}$ in fcc and bec by the factor 10; diffusion of $\mathrm{Ni}$ in bcc and $\mathrm{Ni}$ in fcc have the strongest effect on the kinetics in stage 1 
and 2 , respectively.

Figure 6a): Prediction of austenitization with $6 \mathrm{~K} \cdot \mathrm{min}^{-1}$ by kinetics modeling with different domain sizes, i.e. considering different martensite lath widths; Figure 6b): Simulation of austenitization with 6 K. $\mathrm{min}^{-1}$ with nucleation barriers of 50 and 100 J.mol-1 compared to simulation without nucleation barrier. The data points indicate nucleation and the broken lines discontinuities from a numerical artefact. The effect of the nucleation barrier is only apparent from the magnification displayed in the inset. 
Tables

Table 1- Chemical composition of the investigated X4CrNiMo16-5-1 SMSS determined with Optical emission spectroscopy balanced with Fe (wt \%)

\begin{tabular}{l|l|l|l|l|l|l|l|l|l}
$\mathrm{Fe}$ & $\mathrm{C}$ & $\mathrm{N}$ & $\mathrm{Cr}$ & $\mathrm{Ni}$ & $\mathrm{Mo}$ & $\mathrm{Mn}$ & $\mathrm{Si}$ & $\mathrm{P}$ & $\mathrm{S}$ \\
\hline bal. & 0.03 & 0.037 & 15.00 & 5.80 & 1.03 & 0.86 & 0.39 & 0.025 & 0.008
\end{tabular}


Experiment

In-Situ synchrotron XRD

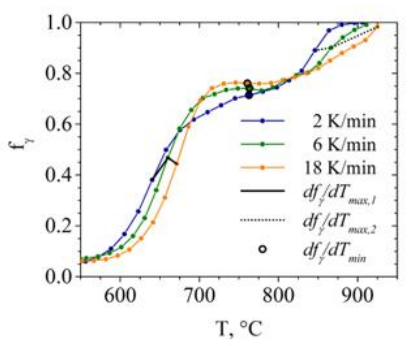

Austenitization with

two-step kinetics

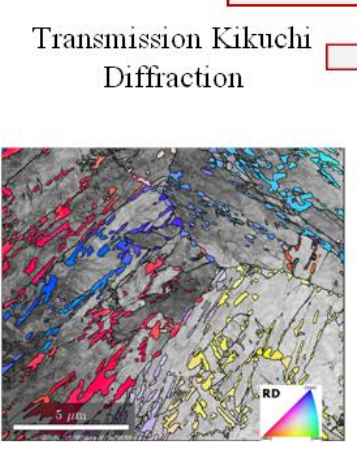

Kinetics Modeling lath-boundaries
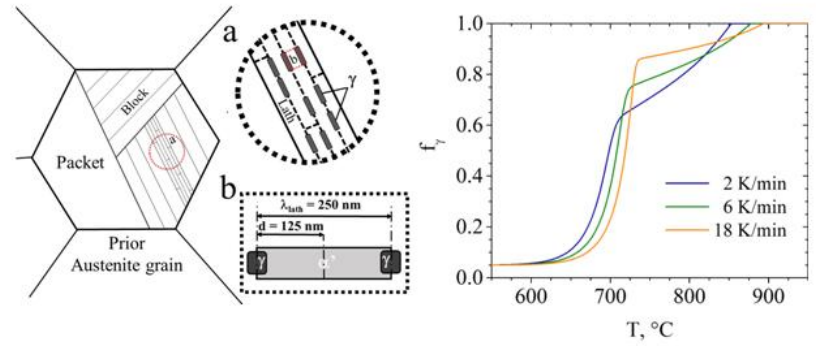

\section{Graphical Abstract}




\section{Highlights}

1. The in situ measured two-stage austenitization kinetics in X4CrNiMo16-5-1 supermartensitic stainless steel can be predicted by using kinetics modeling.

2. The rate of the first stage of austenitization is determined by Ni-diffusion in the body-centered-cubic martensite lattice.

3. The rate of the second stage of austenitization is determined by Ni-diffusion in the face-centered-cubic austenite lattice. 